\title{
What is hidden in the biodiversity? The role of natural products and medicinal chemistry in the drug discovery process
}

\author{
ELIEZER J. BARREIRO
}

Laboratório de Avaliação e Síntese de Substâncias Bioativas (LASSBio), Instituto de Ciências Biomédicas, Universidade Federal do Rio de Janeiro, Avenida Carlos Chagas Filho, 373, Bloco K, $2^{\circ}$ andar, Sala 023, 21941-910 Rio de Janeiro, RJ, Brazil

Manuscript received on March 14, 2019; accepted for publication on May 3, 2019

How to cite: BARREIRO EJ. 2019. What is hidden in the biodiversity? The role of natural products and medicinal chemistry in the drug discovery process. An Acad Bras Cienc 91: e20190306. DOI 10.1590/0001-3765201920190306.

\begin{abstract}
This manuscript describes the role of natural products in the process of drug discovery. In fact, several different natural compounds have been used as inspiration to develop new drugs. Some relevant examples are presented in chronological order.
\end{abstract}

Key words: medicinal chemistry, natural biophores as drug scaffolds, natural products as lead-compounds to drugs, new drugs candidates.

\section{INTRODUCTION}

The role of natural products (NP) in the drug discovery process have been well established from several centuries. The possibility of finding new drugs and precursors from natural sources is one of the more commonly cited reasons for preserving biodiversity. Many publications were dedicated to this subject, describing the relevance of the $\mathrm{NP}$ as source of different and original molecular scaffolds. Also, it is numerous the classes of NP from plants, microorganisms and from the sea. From this great structural variety of bioactive NP, the alkaloids class are very representative. It is possible to recognize in many molecular pattern of drugs, coming from several different classes of alkaloids (Kingston 2011).

Medicinal Chemistry (MedChem) as discipline have begun at Pasteur Institute in the first decade of

E-mail: ejbarreiro@ccsdecania.ufrj.br

ORCid: https://orcid.org/0000-0003-1759-0038 $20^{\text {th }}$ Century, when Pierre Roux, its Director at that time, invited Ernest Fourneau to start a lab, that he named Laboratoire de Chimie Pharmaceutique, where Daniel Bovet worked, some years after 1911. The work of Fourneau and its prestigious coworkers, and the concepts coming from the seminal works of Fischer \& Ehrlich in Germany, both Nobel prize winners in the beginning of $20^{\text {th }}$ Century, gave the scientific basis of MedChem as discipline.

As defined by the Committee of MedChem of IUPAC, medicinal chemistry is a chemistrybased discipline concerned with the design, discovery, and synthesis of drugs (Lima 2007). This discipline combines expertise from chemistry and pharmacology to identify, chemical agents (i.e. small molecules) that has a therapeutic use and to evaluate the molecular properties of existing drugs. It is a translational discipline concerning the drug discovery process. 
NATURAL PRODUCTS \& MEDICINAL CHEMISTRY IN THE DRUG DISCOVERY

Coming from South America, curare is a common name for various plant extract alkaloid arrow poisons used by South American natives in hunting and fishing. (D)-Tubocurarine (1) was isolated as the active principle, in 1935, by Harold King in London, working in Sir Henry Dale's laboratory. Its chemical structure was studied by Daniel Bovet, a medicinal chemist working in Institute Pasteur in Paris, under direction of Ernest Fourneau. Bovet identified the different pharmacophoric contribution in tubocurarine molecule. He was responsible for the understanding of the SAR of these compounds which furnished ganglionic blockers class of drugs, that inhibits transmission between preganglionic and postganglionic neurons in the autonomic nervous system, by acting as a nicotinic acetylcholine receptor (nAChR) antagonist.

Let's consider a second South American molecule, represented by quinine (2). This alkaloid was isolated from Peruvian plant Cinchona officinalis, by Pelletier and Caventou in École de Pharmacie in Paris in the beginning of $19^{\text {th }}$, motivated by its antimalarial properties, discovered by the Amerindians. Its structure was elucidated only in the next $20^{\text {th }}$ Century and its first synthesis was performed by Woodward and Doering, in 1944 (Woodward and Doering 1944). From this natural scaffold, the quinoline core was the origin of synthetic quinoline and isosteres antimalarial compounds as mepacrine, primaquine and chloroquine, all described in the first half part of the $20^{\text {th }}$ Century.

The discovery of contraceptives - The Pill - also is very illustrative of the relevance of NP and medicinal chemistry. From diosgenin (3) (Kim and Park 2018) a phytosteroid sapogenin, the product of hydrolysis by acids, strong bases, or enzymes of saponins, extracted from the tubers of Dioscorea wild yam, such as the Kokoro. The sugar-free (aglycone) product of such hydrolysis, diosgenin obtained from Mexican cactus Cabezade-Negro, was used for the commercial synthesis of progesterone, and other steroid products, by Russell Marker as natural building block to first obtain large amounts of synthetic progesterone (4), essential to undertanding the role of this biological compound in physiology of human reproduction. From this knowledge, some years after, in Syntex laboratories, Carl Djerassi and George Pincus discovered the birth controll pill. The first was norethisterone (5), synthesized by Luis Miramontes, a Mexican chemist working at Mexican Syntex company and at Universidad Autonoma in Mexico City.

The discovery of the antihypertensive drug acting as angiotensin-converting enzyme (ACE) inhibitors, represented by the captopril (6), is also a representative example of the relevance of the collaboration between NP and Medicinal Chemistry (MedChem) to find new innovative drugs (Harvey, 2015). The research effort of the group of Professor Rocha e Silva at University of São Paulo at Ribeirão Preto city, Brazil, working with the poison of Jararaca snake, in order to understanding the pharmacological basis of the tissue necrosis promoted by the serpent bite, conduct to discovery of bradykinin, a peptide comprising nine amino-acid residues that causes contraction of smooth muscle and dilation of blood vessels. This discovery has furnished the molecular basis to understanding of the renin-angiotensin system (RAS) to control of arterial pressure. The structure elucidation of peptide bradykinin was the initial inspiration to captopril, the first drug possessing a primary thiol functionality, developed by medicinal chemists at Squibb laboratories. In fact, the presence of the sulfur atom in this drug is critical to coordinate to the zinc metal present in the active site of the ACE. Captopril (6) was the first in class drug of ACE inhibitors followed by several me-too drugs. 
Drug scaffolds of synthetic small molecules are commonly simple structures, without any chiral center. The chemotherapy of cancer gave us a different view (Demain and Vaishnav 2011). In fact, many natural products with large chemical diversity are described as anticancer drugs. In fact, two drugs were identified by the same research team leader by Wall and Wani at Research Triangle Park laboratories in North Caroline USA from different plants (Kinghorn and Powell 2004). Taxol ${ }^{\mathrm{TM}}$ from Taxus brevifolia and the camptothecin (7) from Camptotheca acuminate (Wall and Wani 1996).

Despite of chemical structural diversity both compounds have in common the used as parenteral administration, due the low oral bioavailability properties.

An enormous research effort has been done by academic and industrial laboratories in order to circumvent this drawback and hundred derivatives were synthesized from these natural products (Barreiro and Bolzani 2009).

Camptothecin was isolated in 1963, as yellow crystals by Monro Wall and Mansukh Wani at Res Triangle Park, NC, USA. It is an alkaloid derived from the bark of Camptotheca acuminate (Mukherjee et al. 2001). In 1969, Wall and Wani isolated the 10-hydroxy-camptothecin that originated topotecan (8), a drug developed by GSK launched 1996 to control cancer (Cragg et al. 2012, Newman and Cragg 2012).

Epothilones were the first 16 members macrocycle approved for treatment of metastatic breast cancer (Shewach 2009). The lactone macrocyclic present in the structure of epothilone-A (9a) and B (9b), having only a methyl group as main structural difference between both natural compounds, introduce a chemical lability to these derivatives that was circumvented by medicinal chemists applying rational molecular modification strategy. Changing the lactone ring to a lactam one by interchange of the oxygen atom of the lactone ring by a nitrogen atom, rising the lactam system.
This strategy produced ixabepilone (10) (Cobham and Donovan 2009) developed by BMS and launched in 2007.

Building blocks of drug-like molecules and drugs are of high interest in drug discovery. The statins were a remarkable example of success of the cooperative work between natural product and medicinal chemists. In 1975, Endo described the structure of mevilonin (11), a terpene natural product isolated from Penicillium citrinum, a fungi strain studied at Sankyo laboratories, in Japan. The molecular similarity between the lactone core of this NP and mevalolactone, the natural substrate of hidroxymethylglutaryl Co-A reductase (HMGCo$\mathrm{AR}$ ), an important enzyme in the biosynthesis of cholesterol, give to Endo the possibility to assay his compound as HMGCo-AR inhibitor. From this scaffold Patchett at Merck company (Patchett, 1993), designed lovastatin (12) (Brenner et al. 1992) the first commercial statin, precursor of simvastatin (13) (Cordell and Colvard 2012) the optimized molecule. Belonging to statin class is the top-1 worldwide sales drug, represented by atorvastatin (14) (Dias et al. 2016) from Pfizer, with US\$ 150 billion of sales during the patent protection period.

As evidenced here mother nature produce very creative and original molecular scaffolds that usually presents new pharmacological mechanism of action for new innovative drugs.

Curiously $c a .80 \%$ of the core ring scaffolds present among natural products are surprisingly absent among commercially available chemical libraries. The main medicinal chemist role is domesticate natural product compounds, to produce a better therapeutic useful compounds. It's worthy mention that still nowadays, the most common molecular scaffolds present in commercial drug are aromatic heterocycles core. In contrast, is very rare find alicyclic moieties in drug marketed structures.

At Laboratório de Avaliação e Síntese de Substâncias Bioativas (LASSBio) of Universidade Federal do Rio de Janeiro (Brazil) it has been 


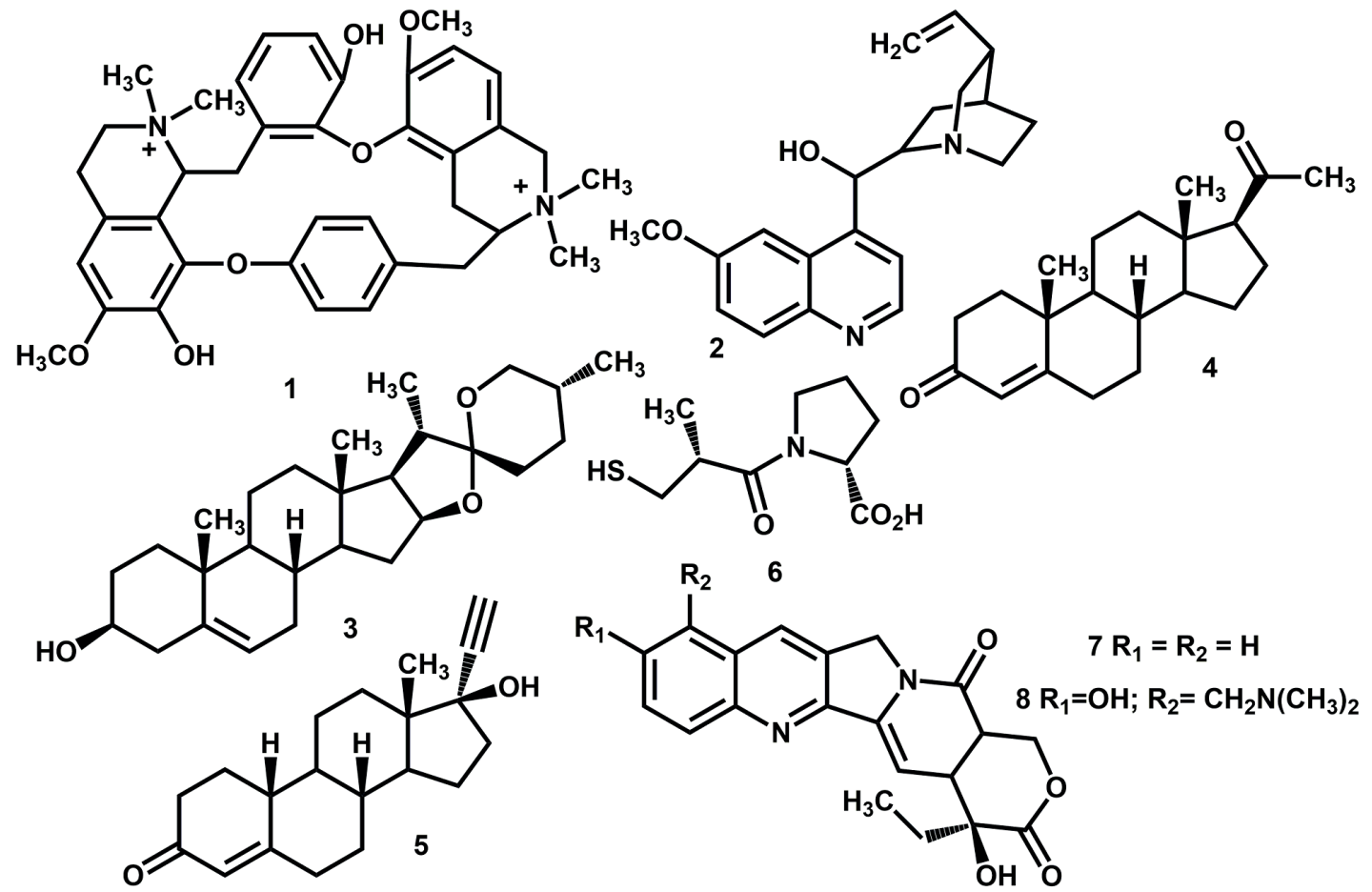

Figure 1 - Structures 1 to 8 .

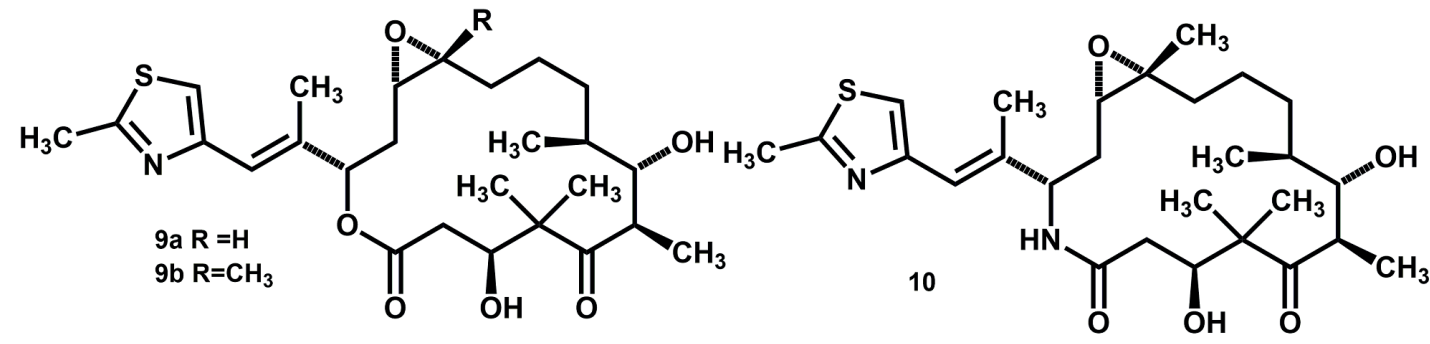<smiles>CC(O)C[C@@H](O)CCn1c(-c2ccccc2)c(-c2ccc(F)cc2)c(C(=O)Nc2ccccc2)c1C(C)C</smiles><smiles>[R]C1C=C2C=C[C@H](C)[C@H](CCC3C[C@@H](O)CC(=O)O3)[C@@H]2[C@H](OC(=O)C(C)CC)C1</smiles>

$11 \mathrm{R}=\mathrm{H}$ $12 \mathrm{R}=\mathrm{CH}_{3}$<smiles>CCC(C)(C)C(=O)O[C@H]1C[C@@H](C)C=C2C=C[C@H](C)[C@H](CCC3C[C@@H](O)CC(=O)O3)[C@H]21</smiles>

Figure 2 - Structures 9 to 14. 
done a major research effort in order to explore abundant Brazilian natural products as structure building blocks to obtain more attractive bioactive compounds. For instance, it have been studied monocrotaline (14a), a pyrrolizidine alkaloid abundant in Crotalaria retusa, an invasive plant found at the UFRJ Campus at Rio de Janeiro City. From this NP was prepared the pheromone of Danaid butterfly. As a second great research effort have been done also the hemisynthesis of new prostaglandins analogues (16), from hidnocarpic acid (15), isolated from Carpoutroche brasiliensis (Lopes,1982). Another abundant alkaloid, spectaline (17), isolated from Cassia leptophylla was possible to prepared new acetylcholinesterase (AChE) inhibitors. Another NP largely employed by LASSBio in the synthesis of bioactive compounds from natural products, it have been used safrole (18), a natural allylbenzene product, occurring in the essential oil of Ocotea pretiosa, it have been synthesized many bioactive compounds, among them LASSBio-294 (19) (Barreiro, 2002), a powerful cardioactive compound belonging to $N$-acylhydrazone class. Further, all preclinical studies were accomplished with LASSBio-294 and this compound represents a new cardioactive drug candidate with inotropic and vasodilator properties, acting by a new mechanism of action (MoA).

\section{FINAL REMARKS}

In this brief report it was described from a personal point of view, the main aspects of the role of natural products chemistry in the discovery of new drugs. The relevance of the cooperative work between natural product and medicinal chemist has been emphasized to contribute for the discovery of the molecular pattern hidden in the biodiversity and their further application in drug discovery and development process.
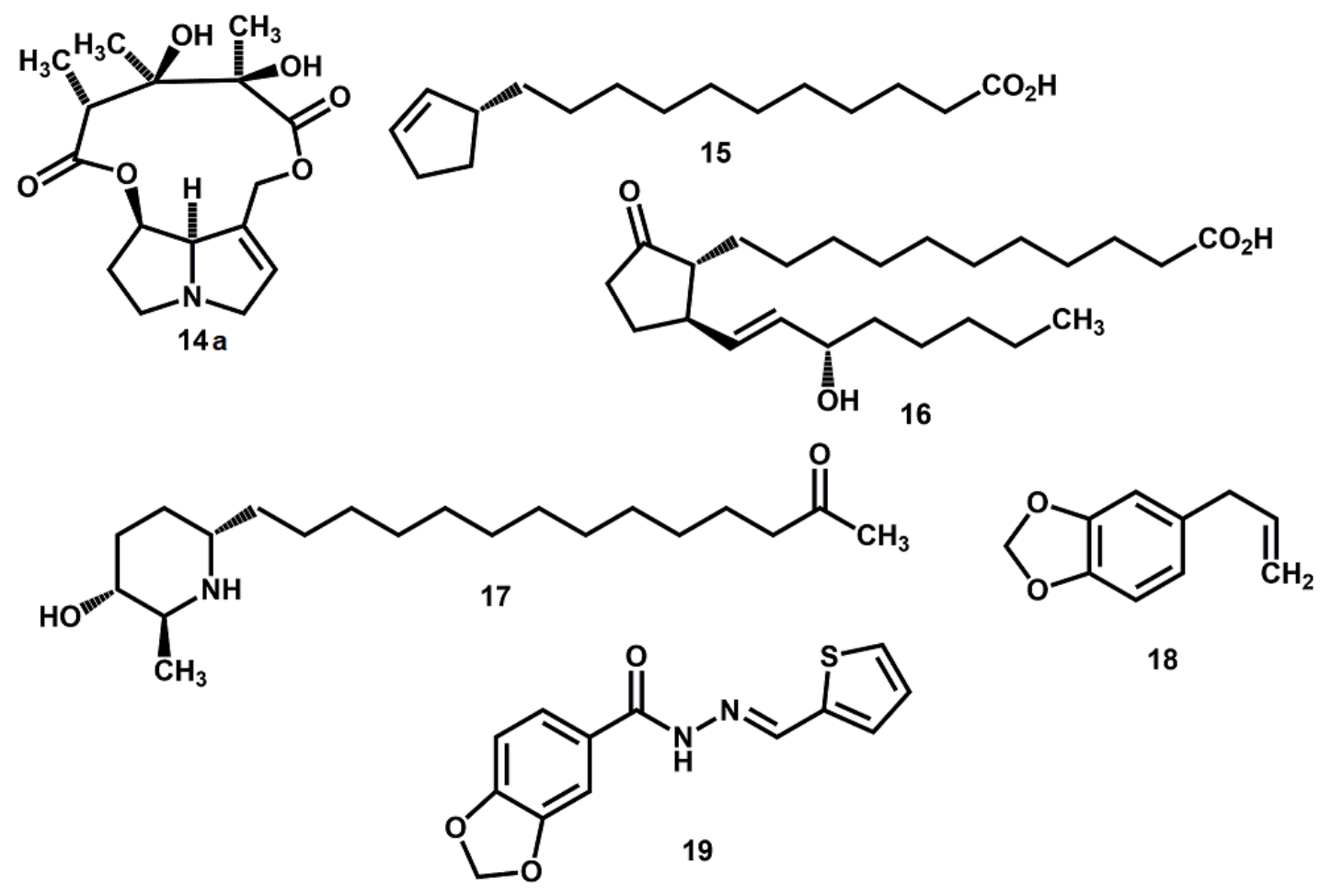

Figure 3 - Structures 14a to 19. 


\section{ACKNOWLEDGMENTS}

I would like to thank $\mathrm{ABC}$ for the invitation to participate at Bilateral Meeting BR-FR, "What is hidden in the biodiversity (Pharmacology \& Natural Products)", that resulted in this manuscript, specially to Professors Adalberto Val \& Vivaldo de Souza.

The research results described in this manuscript, was performed at LASSBio/UFRJ and financially supported by Conselho Nacional de Desenvolvimento Científico e Tecnológico (CNPq, INCT-INOFAR).

\section{REFERENCES}

BARREIRO EJ. 2002. Estratégia de simplificação molecular no planejamento racional de fármacos: A descoberta de novo agente cardioativo. Quim Nova 25: 1172-1180.

BARREIRO EJ AND BOLZANI VS. 2009. Biodiversidade: fonte potencial para a descoberta de fármacos. Quim Nova 32: 679-688.

BRENNER GS, ELLISON DK AND KAUFMAN MJ. 1992. Lovastatin. Anal Profiles Drug Subst Excip 21: 277-305.

COBHAM MV AND DONOVAN D. 2009. Ixabepilone: a new treatment option for the management of taxane-resistant metastatic breast cancer. Cancer Manag Res 1: 69-77

CRAGG GM, GROTHAUS PG AND NEWMAN DJ.2012. Natural Products in Drug Discovery: Recent Advances. In: Cechinel-Filho V (Ed), Plant Bioactives \& Drug Discovery: Principles, Practice, and Perspectives, $4^{\text {th }}$ ed., J Wiley \& Sons, New York, USA, p. 320-410.

CORDELL GAAND COLVARD MD. 2012. Natural products and traditional medicine: turning on a paradigm. J Nat Prod 75: 514-525.
DEMAIN AJ AND VAISHNAV P. 2011. Natural products for cancer chemotherapy. Microb Biotechnol 6: 687-699.

DIAS LC, VIEIRA AS AND BARREIRO EJ. 2016. The Total Synthesis of Calcium Atorvastatin. Org Biomol Chem 14: 2291-2296.

HARVEY AL. 2015. The re-emergence of natural products for drug discovery in the genomics era. Nat Rev Drug Discov 14: 111-129.

KIM JK AND PARK SU. 2018. An update on the biological and pharmacological activities of diosgenin. Excli J 17: 24-28.

KINGHORN AD AND POWELL RG. 2004. Special Issue for Monroe Wall and Mansukh Wani. J Nat Prod 67: 127-128.

KINGSTON DG. 2011. Modern natural products drug discovery and its relevance to biodiversity conservation. J Nat Prod 74: 496-511.

LIMA LM. 2007. Química medicinal moderna: desafios e contribuição brasileira. Quim Nova 30: 1456-1468.

LOPES LN. 1982. Síntese de prostaglandinas modificadas a partir de ácido hidnocárpico. Master's thesis, Departamento de Química Orgânica, Universidade Federal do Rio de Janeiro, Rio de Janeiro, RJ, Brazil. (Unpublished).

MUKHERJEE AK, BASU S, SARKAR N AND GHOSH AC. 2001, Advances in Cancer Therapy with Plant Based Natural Products. Curr Med Chem 8: 1467-1486.

NEWMAN DJ AND CRAGG GM. 2012. Natural products as sources of new drugs over the 30 years from 1981 to 2010 . J Nat Prod 75: 311-335.

PATCHETT AA. 1993. Excursions in drug discovery. J Med Chem 36: 2051-2058.

SHEWACH D. 2009. Introduction to cancer chemotherapeutic. Chem Rev 109: 2859-2861 (Special Issue).

WALL ME AND WANI MC. 1996. Camptothecin and taxol: from discovery to clinic. J Ethnopharmacol 51: 239-254.

WOODWARD RB AND DOERING WE. 1944. The total synthesis of quinine. J Am Chem Soc 66: 849-849. 